\title{
Economics of farm safety: The Nigerian scenario
}

\author{
Olowogbon S. T. ${ }^{1 \star}$, Fakayode S. B. ${ }^{2}$, Jolaiya A. J. ${ }^{2}$ and Adenrele A. Y. ${ }^{1}$ \\ ${ }^{1}$ Occupational Health and Safety Division of Vertext Media Ltd., Ibadan, Oyo State, Nigeria. \\ ${ }^{2}$ Department of Agricultural Economics, University of Ilorin, Ilorin, Kwara State, Nigeria.
}

\begin{abstract}
Accepted 31 May 2012
Investing in farm safety is a win-win game. Apart from improving the financial bottom line of a farm business, it increases and improves the labour productivity of farm workers, which in turn improve agricultural sector. Consequently, agricultural accidents place a great burden on the economy resulting in reduced return on investment (ROI) in agriculture and the burden of injuries/illness (BOI) is increased. This impedes efficiency of the workers, decreased agricultural output and profitability. The dearth of information on the economic relationship of farm safety and ROI, especially in agriculture with focus on a developing country like Nigeria stimulated this research by assessing the economic implication of farm safety practices on agriculture in Nigeria. 100 respondents with agriculture as primary occupation were randomly selected from farming households in Ibadan, Nigeria. Health and work performance questionnaire (HPQ), work limitation questionnaire and interview schedule were adopted for data collection. The research revealed that about 80 and $75 \%$ of the respondents had severe wrist/hand injury and lower back pain, respectively which are work related. $63 \%$ of the respondents on average have been prevented from doing their work as a result of occupational injuries and illness which leads to lost time, restricted work cases and fatalities leading to production loss. Also, $80 \%$ of the respondents do not use any form of personal protective equipment (PPE). Inadequate information and awareness coupled with cost implication were ranked highest on the farm safety adoption constraint list. Thus, information dissemination on farm safety, a subsidized well implemented farm safety programme and farm accident record keeping are recommended.
\end{abstract}

Key words: Nigeria, farm safety, economics.

\section{INTRODUCTION}

The realization of the African Green Revolution and its contribution to food security and economic growth in SubSaharan Africa is threatened by many factors (Ngigi, 2009). The direct effect of these factors on agricultural production and food security will be exacerbated by greater exposure to occupational diseases and illnesses that reduce labour productivity. Sub-Saharan Africa countries have more than 54,000 fatal occupational accidents annually; approximately, 42 million workrelated accidents took place that caused at least three days' absence from work; the fatality rate of the region is 21 per 100,000 workers; the accident rate is 16,000 per 100,000 workers; and the fatal accident rate in agriculture

\footnotetext{
*Corresponding author. E-mail: olowogbonsam@yahoo.com.
}

is 22.5 per 100,000 (Hämäläinen, 2005). On a global scale, agricultural accidents place a great burden on the economy, resulting in reduced return on investment $(\mathrm{ROI})$ in agriculture; moreover, the burden of injuries/illness (BOI) is on the increase. This impedes workers' efficiency, decreases agricultural output and weakens productivity.

Farm safety is therefore a focal issue for improved agricultural productivity; with the expansion of agricultural technology, there is a growing health concern that agricultural workers will face, in addition to traditional health risks with the new occupational health and safety hazards. Even in countries where the primary health care is well developed, occupational health care in agriculture is often non-existence. Nigerian farmers have little or no knowledge of health and safety as it relates to agriculture. Agriculture as practiced today in some countries is crude 
and unsafe, exposing millions of workers to hazards with many sustaining injury and probably death (Mostafa, 2003). The issue of health and safety in agriculture is inconsequential in a developing nation like Nigeria or if at all considered, it is still at a very low ebb or non-existence despite the fact that agriculture is the mainstay of her economy. Agriculture was the most important sector of the economy before the decline in the 1970s due to oil boom. It created jobs and generated employment, and engaged about $70 \%$ of the labor force (Kwanasahi et al., 1998). A greater fraction of the country's population of over 167 million depends on agriculture for their livelihood today either directly or indirectly. Unfortunately, this sector is deep seated culture of unwise risk taking and lack appreciation of the role of good health and safety management (Chris, 2008). Farm workers are exposed to hazard ranging from chemical, physical, ergonomics, biological and psychosocial hazards thereby leading to disorders such as musculoskeletal disorder and diseases like carcinogenicity (cancer causing), mutagenicity (induce mutations), tetragenicity (affect the fetus), psychiatric disorder and delayed neuropathy, and the dusts have been known to cause diseases ranging from byssinosis, occupational asthma, pneumonitis and non-specific chronic obstructive pulmonary disease (COPD) (Mostafa, 2003). After construction, agricultural sector has the worst record for work related fatalities and one of the worst for occupational ill health and injuries (Chris, 2008).

A healthy workforce is definitely one of the most important economic assets to a nation. An unhealthy workforce on the other hand is an economic loss to a nation which in turn affects productivity (Karen et al., 2005). At the individual level, good health can directly increase general output (e.g. through reduced absenteeism, injury and illnesses as well as improved morale and general work-well being. Consequently, economists and historians have focused much attention on better understanding of productivity determinants. There is an increasing awareness that human capital is a key factor. Recently, however, increasing attention has been given to health as a form of human capital (Emile, 2002). Poor health state erodes human capital and reduces resilience to shock and reduces productivity as well as impaired physical and mental capacity (Soekirman, 2010).

\section{A need for farm safety programme}

According to International Labour Organization (ILO) report in 2000, as cited by Oluwagbemi (2007), revealed that $170,000(50.7 \%)$ agricultural workers are killed each year from the total of 335,000 in fatal workplace accidents worldwide. Therefore, special attention is needed for the health and safety of agricultural workers, who constitute three quarters of the Nigerian working population. Health and safety has been identified to have a strong influence and invaluable to any sector of the economy. Effective management of health and safety can help to deliver improved productivity and efficiency. It has been tied to positive performance indicators (PPIs) (Smallman and John, 2001). "Agriculture" covers not only farming, but also many other associated activities such as crop processing and packaging, irrigation, pest management, grain storage, animal husbandry, construction and agricultural work also refer to as domestic tasks (carrying water or fuel-wood, etc). The distinguishing characteristics of agricultural work is the fact that it is carried out in a rural environment where there is no clear-cut distinction between working and living conditions. As agricultural work is carried out in the countryside, it is subject to the health hazards of a rural environment as well as those inherent in the specific work processes involved (ILO, 1996). Due to the nature of agricultural work, workers in this sector are prone to many hazards; hence, there is a need for farm safety programme for workers. Recent innovation in agriculture has also added drastically to the dangers or hazards faced by farm workers. Effective health and safety programme should be in place to mitigate the effect of such hazards.

Nigeria has little or no data on workers health and safety record in agriculture probably because the workers are peasant and rural dwellers coupled with the fact that they are insensitivity to the role safety can play in the development and productivity of the sector. The dearth of information on the economic relationship of farm safety and ROI especially in agriculture with focus on a developing country like Nigeria stimulated this research. This research intends to bridge this gap by assessing the economic implication of farm safety practices on agriculture in Nigeria.

\section{MATERIALS AND METHODS}

This study was carried out in Ibadan metropolis in Oyo State, Nigeria. The state has thirty-three local government areas. Its population is $1,338,659$ according to census results for 2006, with coordinates $7^{\circ} 23^{\prime} 47^{\prime \prime} \mathrm{N}, 3^{\circ} 55^{\prime} 0^{\prime \prime} \mathrm{E}$ and Area $1,189.2\left(3,080 \mathrm{~km}^{2}\right)$. Ibadan has a tropical wet and dry climate, with a lengthy wet season and relatively constant temperatures throughout the course of the year. Ibadan wet season runs from March through October, though August sees to an extent a break in precipitation. This lull nearly divides the wet season into two different wet seasons. The remaining months form the city's dry season. Like a good portion of West Africa, Ibadan experiences harmattan between the months of November and February. Agriculture is the main occupation of the people of Oyo State. The climate in the state favours the cultivation of crops like maize, yam, cassava, millet, rice, plantains, cocoa, palm produce, cashew, etc (Ibadan Wikipedia, 2011). Data were obtained using a health and work performance questionnaire coupled with structured interview schedule, administered to 100 respondents with agriculture as the primary occupation. These respondents were randomly selected from the faming population in the area; this was supplemented with secondary data from reports, publications and internet. Simple statistics such as mean, mode, and Likert scaling were used for the data analysis. BOI are the cost 
Table 1. Result.

\begin{tabular}{|c|c|c|}
\hline Demographic characteristics & Frequency & $\%$ \\
\hline \multicolumn{3}{|l|}{ Age (years) } \\
\hline $20-30$ & 30 & 30 \\
\hline $31-40$ & 40 & 40 \\
\hline$>40$ & 30 & 30 \\
\hline \multicolumn{3}{|l|}{ Sex } \\
\hline Males & 80 & 80 \\
\hline Females & 20 & 20 \\
\hline \multicolumn{3}{|l|}{ Marital status } \\
\hline Single & 20 & 20 \\
\hline Married & 80 & 80 \\
\hline \multicolumn{3}{|l|}{ Religion } \\
\hline Christianity & 40 & 40 \\
\hline Islam & 40 & 40 \\
\hline Traditional & 20 & 20 \\
\hline \multicolumn{3}{|l|}{ Educational background } \\
\hline No formal education & 30 & 30 \\
\hline Primary & 45 & 45 \\
\hline Secondary & 15 & 15 \\
\hline Tertiary & 10 & 10 \\
\hline \multicolumn{3}{|l|}{ Hazard awareness } \\
\hline Yes & 40 & 40 \\
\hline No & 60 & 60 \\
\hline \multicolumn{3}{|c|}{ Personal protective equipment (PPE) usage } \\
\hline Yes & 20 & 20 \\
\hline No & 80 & 80 \\
\hline
\end{tabular}

of occupational injuries and ROI is the returns on investment.

\section{RESULTS AND DISCUSSION}

Table 1 reveals that $80 \%$ of the respondents were male, signifying a male dominated occupation, with a modal age group of 31 to 40 which denote age range of vigour and strength. $10 \%$ of the respondents had tertiary education, and $45 \%$ had primary education as the highest educational level attained, which implies that they have little or no formal education which has be proven to have a strong tie to adoption of innovation and modern practices. This study revealed that $60 \%$ of the respondents are not aware of any inherent hazard in agriculture, this connote the fact that health and safety in agriculture as it relates to occupational health and safety is at a lower ebb in the country; hence, there is a need for awareness campaign. Also, $80 \%$ of the respondents do not use any form of personal protective equipment which still reflect the poor awareness level.

Health and work performance questionnaire (HPQ) questions response

\section{Statistics of respondents that have experienced one form of discomfort in the past 12 months related to their occupation}

Figure 1 reveals that $80 \%$ of the respondents had wrist/hand injury, $75 \%$ had lower back pain and 55\% knee injury in the last 12 months resulting from their job which shows that occupational injury in agriculture is prominent, which is probably due to the poor awareness level of stakeholders in the sector in identifying the roles that health and safety can play in maximizing productivity. 


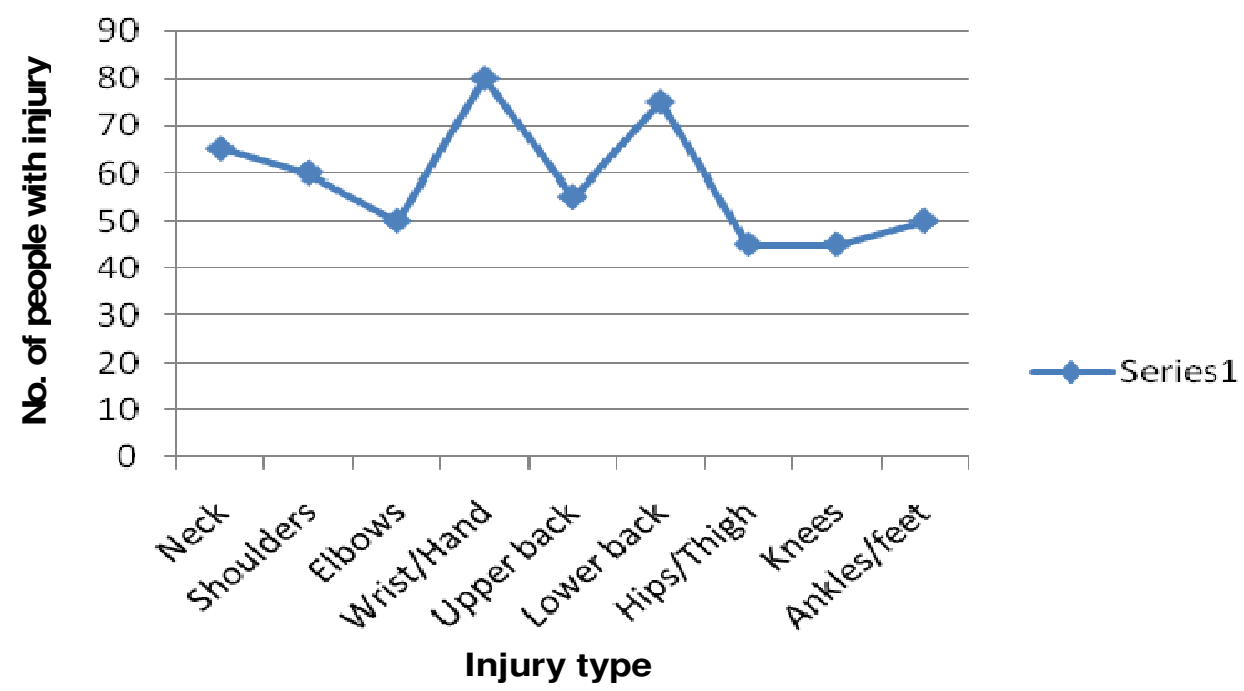

Figure 1. The distribution chart of injury and type

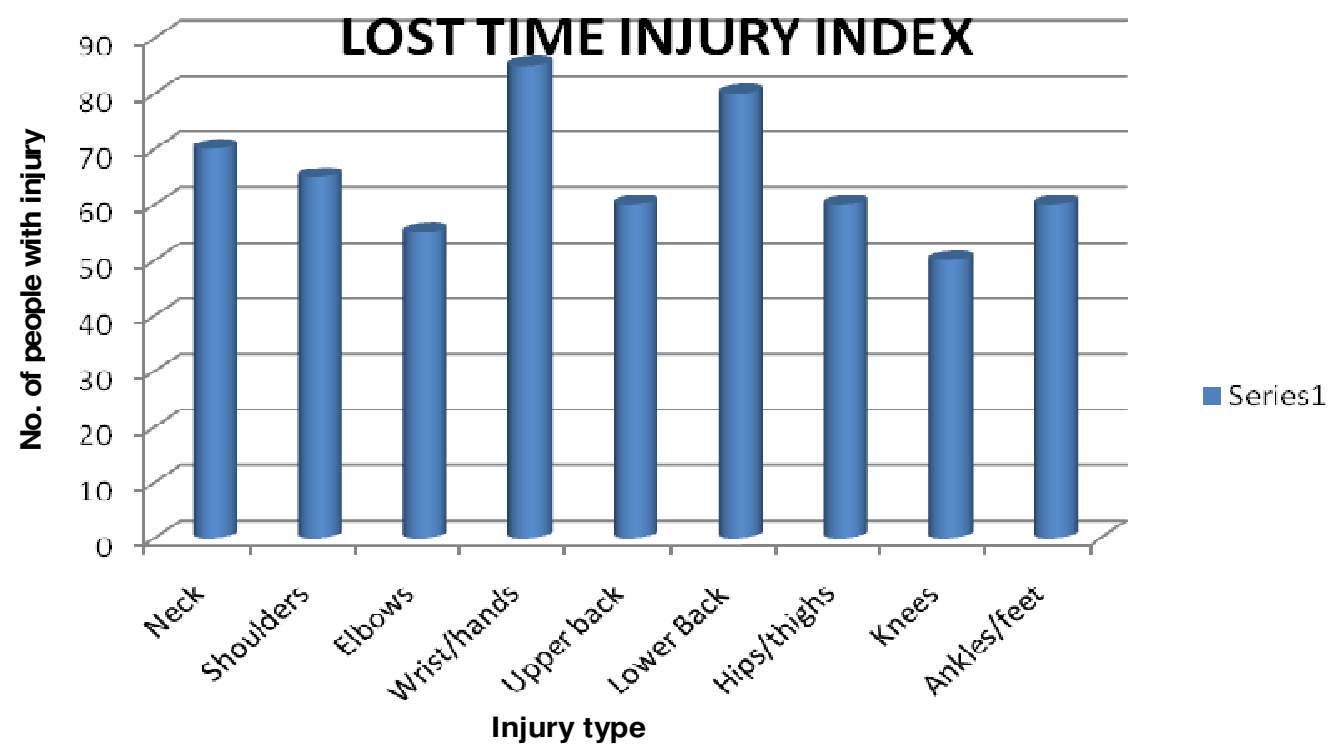

Figure 2. Lost time injury index chart

Statistics of respondents that have at any time during the last 12 months been prevented from doing their work because of discomfort in their body part

Figure 2 reveals that $80 \%$ of the respondents have been prevented from doing their job as a result of wrist/hand injury and $75 \%$ have also been prevented as a result of lower back injury. These occupational injuries or work related injuries have resulted in lost time or lost production and restricted work cases which has reduced productivity. The study also revealed that poor information and awareness (27.6\%) and cost implication $(26.9 \%)$ rank first and second in the adoption constraints list for farm safety programme, respectively. This fact could be linked to poverty and unavailability of farm accidents record and other information on farm safety in Nigeria.

\section{RECOMMENDATIONS}

Based on the findings of this study, the following are recommended:

(1) Formulation and implementation of farm safety policies in Nigeria. 
(2) Adequate information dissemination on farm safety.

(3) Workers in agriculture should be educated/trained on agricultural hazards and means of prevention.

(4) Massive poverty reduction programme, since it is a bottleneck to adoption.

(5) Awareness on usage and the provision of personal protective equipment (PPE) for workers ranging from hang cloves, coveralls, footwear, ear muffs at a subsidized rate.

(6) Extension agents, cooperative societies, and trade unions should be equipped with accurate information so that they can enlighten farmers on the hazards.

(7) Proper record keeping on agricultural health and safety should be encouraged for performance review.

Conclusively, the importance of farm safety to the development of the sector cannot be overemphasized. Human capital such as health has been described as a determinant for productivity, hence the wealth, financial and holistic growth of the sector is a function of the health and well being of workers in the sector. Investing in farm safety programme is therefore a win-win game, because it is better and cheaper to invest in safety rather than bear the cost of working in an unsafe environment.

\section{REFERENCES}

Chris I (2008). Pastoral care, Safety Health Practitioner Magazine, United Media.
Emile T (2002). The Impact of Health on Productivity :Empirical Evidence and Policy Implications. The review of economic Performance and Social Progress.

Hämäläinen P, Takala J, Saarela KL (2005), Global estimates of occupational accidents International Labour Office (ILO), SafeWork, Geneva Switzerland.

Ibadan Wikipedia, (2011) http://www.en.wikipedia.or/wiki/lbadan---retrieved available on line 30:06-11.

Karen D. Collins,SR Michelle MD, Alice H, Alyssa LH (2005) www.commonwealthfund.org/usr doc/856 Davis hlt productivity US workers available on line. 18:03-11.

Kwanasahi M, Ajilima .I, Garba .A (1998). Nigerian economy: response of Agriculture to adjustment policy. www.aerfrica/documents/RD78 .PDF available online. 26:04-10.

Mostafa AB (2003) Health of Agricultural Workers in Agriculture: World Health Regional Publication, Eastern Mediterranean Series 25, Egypt.

ILO (1996): International Labour Organization, Yearbook of Labour Statistics, Geneva)

Ngigi NS (2009). Climate Change Adaptation Strategies: Water Resources Management Options for Smallholder Farming Systems in Sub-Saharan Africa. The MDG Centre for East and Southern Africa of the Earth Institute at Columbia University, New York,USA.

Oluwagbemi BF (2007). Basic Occupational Health and Safety: published by Vertext Media Limited, Ibadan.

Smallman C, John G (2001). 'British directors perspectives on the impact of health and safety on corporate performance', Safety Science, 38: 227-239

Soekirman (2010). Food Security and Nutrition Nexus: Food security seminar at Manila July, 2010. 